\title{
Dispachability Improvement of Wind Generation by the Virtual Power Producers
}

H. Morais, M. Cardoso, N. Saleiro, Z.A. Vale,

L. Castanheira and I. Praça

\begin{abstract}
Nowadays, there is a growing environmental concern about were the energy that we use comes from, bringing the attention on renewable energies. However, the use and trade of renewable energies in the market seem to be complicated because of the lack of guarantees of generation, mainly in the wind farms. The lack of guarantees is usually addressed by using a reserve generation. The aggregation of DG plants gives place to a new concept: the Virtual Power Producer (VPP). VPPs can reinforce the importance of wind generation technologies, making them valuable in electricity markets. This paper presents some results obtained with a simulation tool (ViProd) developed to support VPPs in the analysis of their operation and management methods and of their strategies effects.
\end{abstract}

Keywords: Distributed Generation (DG), Wind power, Virtual Power Producer (VPP), Reserve Management, Electricity Market. 


\section{Introduction}

Electricity generation affects the environment, causes climate change, and associated with it are the concerns and questions about the threats to our way of life. The investment on sustainable environmental policies caused the emergence of a new generation technologies, based on renewable resources. An efficient management with scalable and intelligent planning in a distributed generation environment will help performing this task.

Low emission generation technologies, such as the wind generation technology (IEA, 2002) allow a new repositioning of a significant part of the generation. Those could be distributed and owned by decentralized players, providing a significant amount of the electricity generation presenting economic and technical benefits to the network (Khattam, 2004).

Furthermore, it is encouraged by a regulatory framework favourable to cogeneration and renewable energy as well as by the attractive cost of some equipment and the low cost and flexibility of some primary energy. At this stage the main technologies used are micro and hydro turbines, fuel cells, wind generation, and solar cells (IEA, 2002).

Setting up the generation in a Distributed Generation (DG) model, helps to archive a cleaner and more efficient electricity use. The energy generation near the consumers reduces the waste of energy spent on the incoming energy transmission from the generation plants. In order to archive an even better management, the generation can be associated with attractive high efficiency equipments and combines several technologies such as wind and co-generation.

A deregulated market, where low power rating generators sell their power in the market, could present economic and technical benefits (Khattam, 2004). However, there are serious barriers to the successful participation of these generators in the market, both of

economic

and

technical

nature. 
Currently, DG technology is supported through government policies and subsides, but in the future this type of generation, could be autonomous and act in the competitive market.

In the technical field, we focus on the reserve, because some of the technologies used in DG have problems in resource forecasting, in particular wind and photovoltaic energy are those that need more attention in this respect. In this context the reserve management can be a critical issue to VPPs activities, because, if they have energy surplus or shortage, they can be harshly penalized, depending in the market organization and, mainly, on the penalties.

\section{Virtual Power Producers (VPP)}

The aggregation of DG plants gives place to a new concept: the Virtual Power Producer (VPP). VPPs are multi-technology and multi-site heterogeneous entities. In the scope of a VPP, producers can make sure their generators are optimally operated and that the power that is not consumed in their installation has good chances to be sold in the market. At the same time, VPPs will be able to commit to a more robust generation profile, raising the value of non-dispatchable generation technologies.

Under this context, VPPs can ensure security, environmental friendly generation and optimal management of thermal energy and electricity, as well as optimal operation and maintenance of electrical equipment, including the sale of electricity to the market.

In a deregulated market, generation is scheduled through an open wholesale market where large amounts of electrical energy are traded daily. Marketplaces are today organized over one or several countries, and each marketplace has its own set of rules.

One of the functions of the VPP is to determine the amount of energy to negotiate in the market. This is a complex task namely due to the uncertainty of the generation forecasts.

If a producer is associated to a VPP, the energy delivered by a wind farm can be more optimized. VPPs sell larger quantities of energy and therefore from a producers view, the associated forecasts risks are minimized. The losses caused by penalization in sequence of an overestimated forecast of a specific producer may be compensated by other producer's energy surplus.

In the other hand, VPP has at his disposal an amount of strategies that can avoid penalties for the producers.

VPPs must identify the characteristics of each one of their associates and try to optimize the selling activity so that each associate delivers the biggest possible amount of energy. The ideal situation would be to sell all the energy that its associates are able to produce at each instant, however this is not possible due to the uncertainty of generation of the technologies that depend from natural resources as the wind, sun, waves or water flows.

The method used by the markets to penalize the violation of the established contracts is not uniform, which implies different forms of the VPPs action.

In markets where penalty mechanisms exist, such as the French, the Italian, the Finnish, the Swedish or the British (Table I), the VPPs have to conveniently manage the generation capacity of the associated producers to assure enough reserves, to compensate generation oscillations. 
Table 1 Balancing system

\begin{tabular}{|c|c|c|c|}
\hline Country & $\begin{array}{c}\text { Type of balancing } \\
\text { system }\end{array}$ & $\begin{array}{l}\text { Existence of } \\
\text { penalty } \\
\text { regime }\end{array}$ & Type of penalty regime \\
\hline Denmark & The 'Nordic' system & No & Not relevant \\
\hline Finland & $\begin{array}{l}\text { Every participant needs } \\
\text { to have an 'open } \\
\text { supplier'. Fingrid assures } \\
\text { the balance of the whole } \\
\text { country. }\end{array}$ & Yes & - \\
\hline France & Balancing market & Yes & - \\
\hline Germany & - & No & $\begin{array}{l}\text { Extra price for capacity } \\
\text { component when tolerance } \\
\text { band is exceeded }\end{array}$ \\
\hline Italy & Balancing market & Yes & $\begin{array}{l}\text { Operator imposes penalties } \\
\text { (warning, suspension, } \\
\text { exclusion) }\end{array}$ \\
\hline Norway & $\begin{array}{l}\text { A merit-order list } \\
\text { regulates production up } \\
\text { or down if there is } \\
\text { imbalance. }\end{array}$ & No & Not relevant \\
\hline Spain & $\begin{array}{l}\text { Services managed by the } \\
\text { system operator, which } \\
\text { allocates imbalances to } \\
\text { generation companies } \\
\text { through a competition } \\
\text { mechanism }\end{array}$ & No & Not relevant \\
\hline Sweden & $\begin{array}{l}\text { Balancing market, run by } \\
\text { Svenska Kraftnät }\end{array}$ & Yes & $\begin{array}{l}\text { Higher prices than spot price } \\
\text { for imbalance in the wrong } \\
\text { direction }\end{array}$ \\
\hline $\mathrm{UK}(\mathrm{GB})$ & Balancing market $^{2}$ & Yes & $\begin{array}{l}\text { Imbalance prices calculated } \\
\text { from Balancing Mechanism } \\
\text { bias }\end{array}$ \\
\hline UK (NI) & $\begin{array}{l}\text { Tariff for top-up and for } \\
\text { spill }\end{array}$ & - & $\begin{array}{l}\text { Tariff is the same as for } \\
\text { franchise customers }\end{array}$ \\
\hline
\end{tabular}

Notes: Where no data were provided, this is indicated by a dash (-).

1 - Fingrid maintains power reserves in case of system disturbances. Security of supply has been allocated to National Emergency Supply, an agency which is obliged to acquire the necessary supplies or contracts.

2 - NGC Transmission System Security and Quality of Supply Standard - Issue 2. Sources: Elkraft System AMBA (Denmark), Fingrid System Oy (Finland), DVG

(Germany), GRTN (Italy), Statnett SF (Norway), REE (Spain), Svenska

Kraftnät (Sweden), NGC (GB), NIE (NI) (Oxera, 2001). 
The energy reserves will have to be assured, in the first place, by producers using technologies that allow them to control the net injected power, such as co-generation, fuel cells, or gas turbines. These producers may establish contracts with the VPP, for supplying the imbalance settlement energy, below of theirs nominal capacity.

Another possibility for the VPP to assure some level of reserve is, to have specific plants for that. These plants can be managed by the VPP or by another entity.

However it will have higher costs, essentially in the initial investment. Start-up costs must be considered, to decide what units should be in spinning reserve.

It's also possible to establish contracts with large power plants. These contracts may be bilateral for large periods of time, for example 6 or 12 months, with a fixed power contract, or daily in the spot market, in function of the necessities forecast. If the energy is bought in the market, the purchase price will be equal to the selling price, resulting in profits due to the inexistence of penalties.

If the energy is acquired by bilateral contracts, it will have a fixed value every day and it can be used for reserve or as a part of the production after checking that it is not necessary to use all power for reserve.

The VPP can also adopt a hybrid solution, combing more than one option of reserve, in order to minimize the costs and to diversify options.

The reserve value that the VPP has to guarantee depends basically in the Market, and on the generation technologies that it can use.

If the VPPs have plenty producers without dispatchable technologies, that are physically distant with similar characteristics, it could exist a reserve factor that permits the reduction of the spinning reserve. This factor is given by the forecasts probability of a specific plant, which is producing below the estimative value and according to another that is producing over or according to the estimative value considered by forecasts.

The reserve factor is obtained regarding the experiences and considering the biggest period of time.

One determinant factor will be the wind farm installed capacity. It's not possible to use the reserve factor in the global generation when the capacities are different. In those situations the reserve factor has to be applied only to plants with less installed power.

This factor can be different in each VPP, according to the experience and the operation time of its aggregates.

A possible strategy is to have as reserve the amount of power that guarantees n-1 security. In this case, if the biggest generation unit gets out of service and if all the other producers are operating in accordance with the foreseen, the VPP will be able to continue to guarantee all the established contracts.

Let us consider a VPP with $\mathrm{n}$ associated producers. If this VPP contracts a fixed power value with a thermal producer on an annual basis to use for reserve proposes, we have:

$$
P^{\text {therm }}=P^{i}{ }^{\max }-\sum_{j=1}^{\sum_{n}} R^{j}
$$

Where :

$P_{\text {them }}$ - Contracted Thermal Power

$P_{i}^{\max }$ - No minal Power of the biggest Generation Unit

$j$-Producer Associated to VPP

$R_{j}$ - Contracted Re serve with Associated Producer $j$ 
The VPP can keep this constant reserve value, resulting in a higher security when the sold energy decreases.

Because of that, the VPP can reformulate its strategy, in function of the sold energy, changing the scheduled generation.

The VPP can negotiate the excess reserve with other market agents or the system operator.

When the forecasted generation for the bigger generation unit is lower than its nominal power the required reserve is also lower. In this case, the VPP can sell the exceeding energy in the spot market.

In this situation, we have:

$$
\begin{aligned}
& P_{V P P}=\sum_{i=1}^{n} P_{\text {therm }}^{f}+P_{V P P}-R_{V P} \\
& R_{V P P}=\left(P_{i}^{f}\right)^{\text {max }}
\end{aligned}
$$

\section{Where:}

$P_{V P P}-$ Power that VPP can negociate in the market

$$
R_{V P P}-V P P \text { Reserve }
$$

$P_{i}^{f}-$ Forecasted power for generation unit $i$

Generation and reserve values can change dynamically. In some situations, the n-1 security level cannot be assured.

The bigger penetration of wind energy (and other technologies with similar characteristics) causes lesser generation stability with oscillations around the values foreseen for the reserve and generation. Assuring the required security level, brings higher costs to the VPP but it's useful to avoid penalties by the market operator such as: payments, warning, suspension or exclusion.

Another solution is to guarantee as reserve a percentage of the foreseen generation in each moment. In this situation the power available to negotiation and the reserve are calculated by:

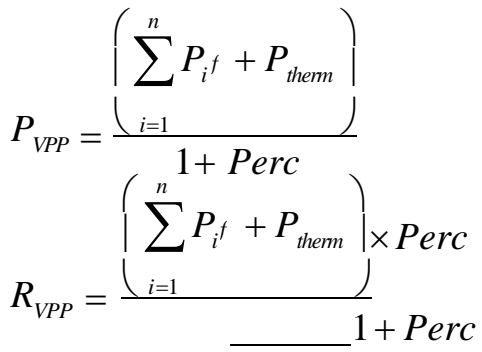

Where :

Perc-Percentage of intended reserve 
There are some markets where contract violations do not imply direct penalties. In those markets the system operator handles the system reserve which is paid in fixed taxes by each seller agent. This methodology does not prevent the inadequate behaviour of seller agents on the market what can impose a tax raise. On the other hand, this situation can promote speculations with the sellers negotiating deliberately energy, without any type of supply guarantee.

\section{SIMULATION TOOL}

A simulation tool, named ViProd, has been developed to simulate the operation of a VPP and his interaction with the market. This tool takes into account the characteristics of the technologies used by the power producers and can be used to provide decision support to VPPs.

ViProd is divided in two different parts: one calculates the generation to the next day and other simulates the generation.

Using this tool, producers can be associated to a VPP and each one of them can produce energy with different technologies and in distinct places. Figure 1 shows a producer with four different technologies.

Figure 1 - Simulation of a producer

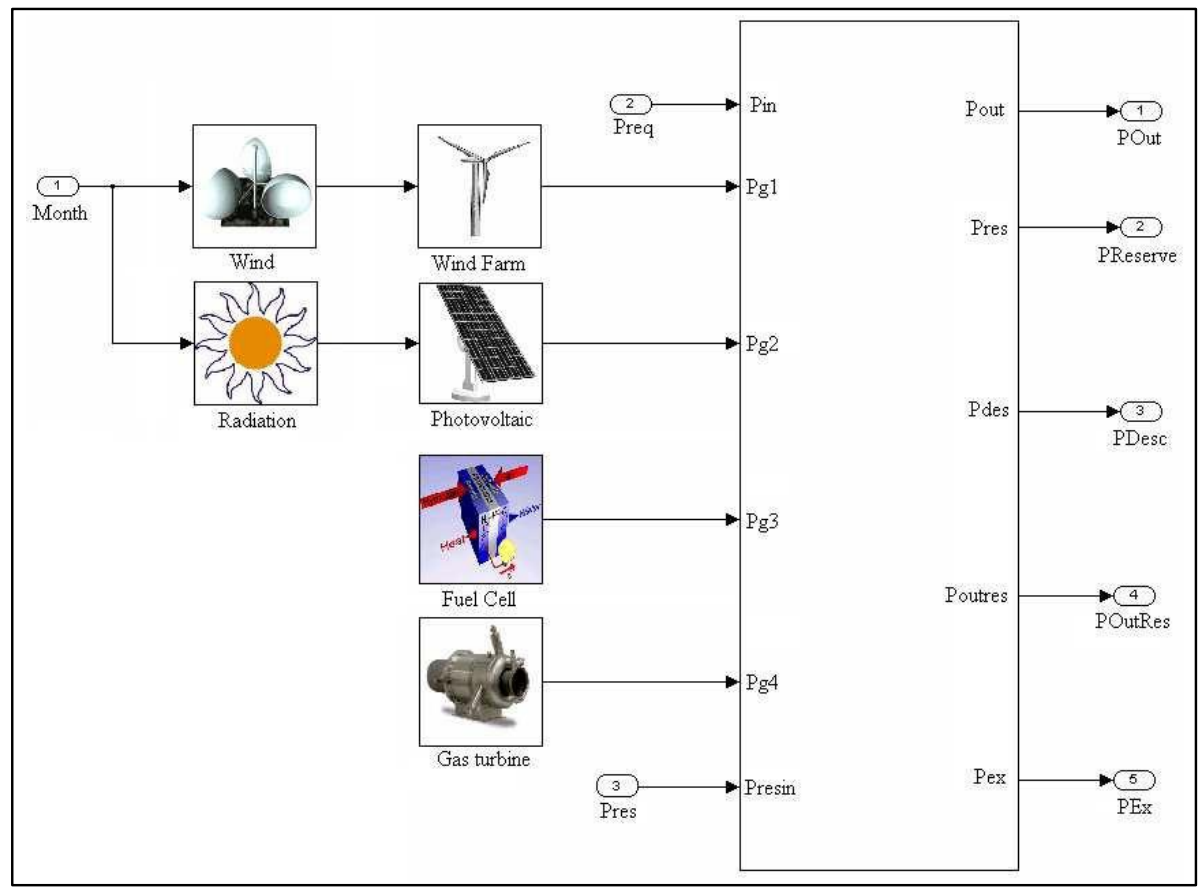

To estimate the generated power by different producers using technologies such us wind power, small hydroelectric and photovoltaic, real information concerning wind, water flows, temperature and radiation has been used. Figure 2 shows the wind simulation. 
Figure 2 - Wind Simulation

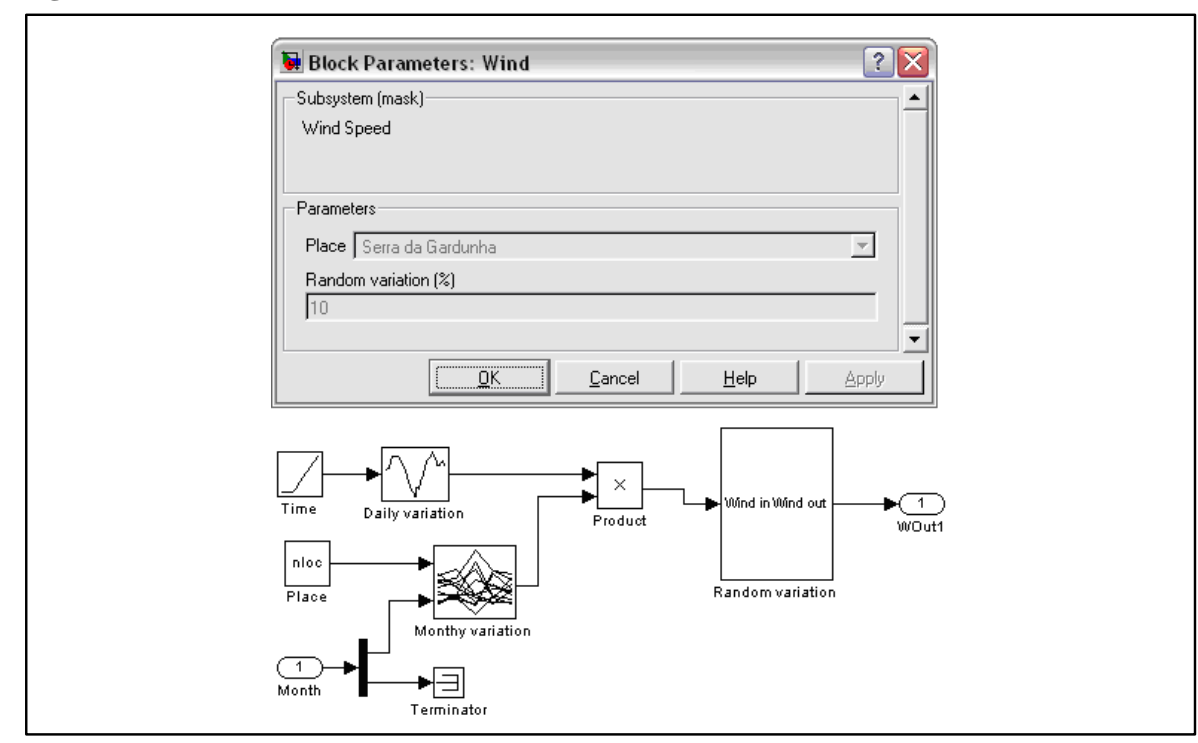

We can define the local and the amplitude of the resource variation related to these phenomenon. A random variation allows the tool to be more realistic, making the forecasting errors dependent from the time to the forecasted situation. This characteristic helps to produce scenarios closer to the reality.

All the considered generation technologies were simulated. Figure 3 shows an aspect of the display concerning a wind farm simulation, considering the curves of power in function of the resources given by the manufacturers.

Figure 3 - Wind farm Simulation

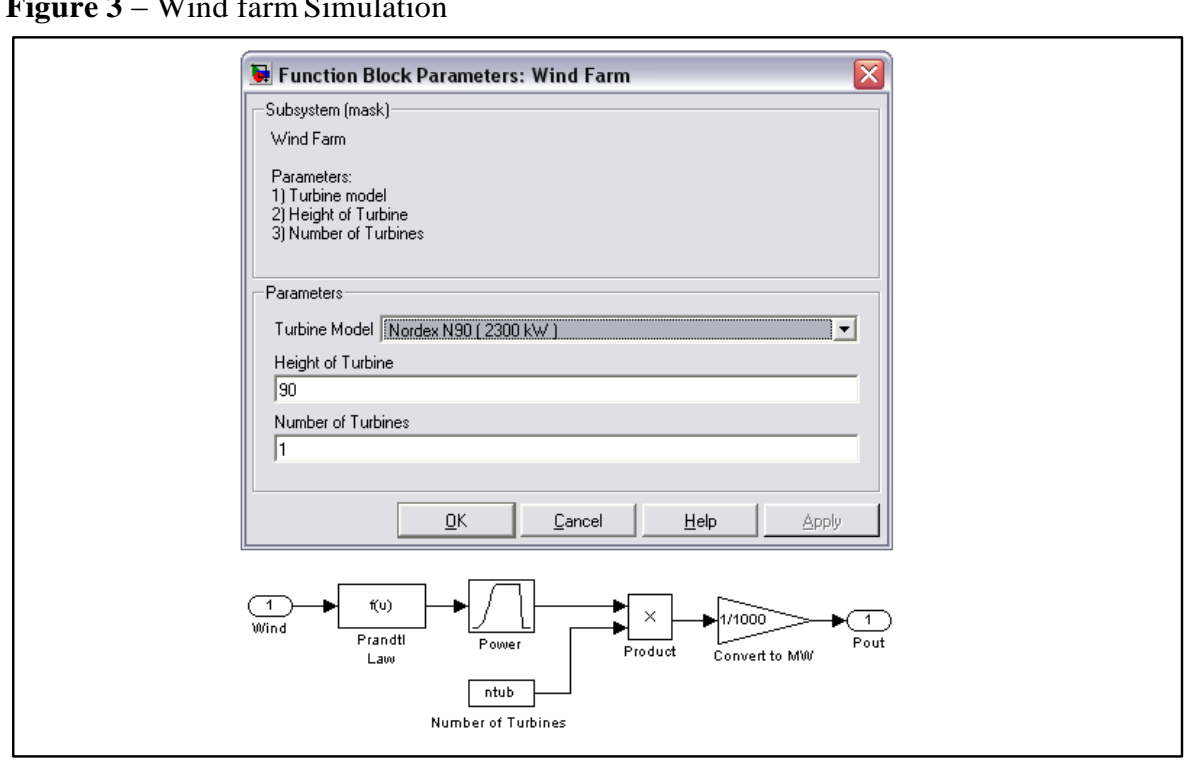


Initially, each producer has to indicate to the VPP, the foreseen generation to the next day, the energy prices, the power reserve and reserve prices. Based on this data, the VPP must compose the bids to the market, according to the already referred criteria.

In case of the technologies that are dispatchable, the producers and the VPP make an agreement to consider some of the available power as reserve to assure the VPP reserve. The reserve value is calculated according to the penetration of non-dispatchable technologies.

The second part of the simulation tool simulates the management of all VPP generation. At the beginning, it makes a dispatch in function of the sold energy, producer's price and their capacity of generation. Later, it controls the generation of the producers and generates the reserves of each one, as excess or lack of generation exists.

The result is that we can check the generation by technology and the reserve that exist at each moment in the system.

\section{Case studies}

With the developed simulation tool, several studies were done, using different levels of reserve. The goal was to test if the amount of reserve power was enough to allow the VPP supplying the sold energy, preventing penalty costs.

In this section we present two case studies. In both, the same simulation is considered for two different days, one of September and another of November, in two different markets (UK and France). All prices are in Euros, considering $1 £=1.45 €$.

In the first case study, we consider several types of producers and the evolution throughout the day, of there generation using different technologies. The simulated Scenarios $(\mathrm{Sc})$ are the following:

- Scenario 1 - Reserve assured by a thermal plant with contracted power equal to the nominal power of the biggest unit $(\mathrm{P}=52 \mathrm{MW})$;

- Scenario 2 - Reserve assured by a thermal plant with contracted power equal to the nominal power of the biggest unit $(\mathrm{P}=52 \mathrm{MW})$. The actual reserve value is adjusted to the maximum value of the foreseen power in each instant, being available remain VPP to commercialize;

- Scenario 3 - Reserve assured by a thermal plant with contracted power of $20 \mathrm{MW}$;

- Scenario 4 - Reserve assured by a thermal plant with contracted power of $10 \mathrm{MW}$;

- Scenario 5 - Reserve assured by a thermal plant with contracted power of $10 \mathrm{MW}$ and by the producers (co-generation, fuel cells, and gas turbines contribute, each one, with $10 \%$ of its generation for reserve power);

- Scenario 6 - Reserve assured by the producers, (co-generation, fuel cells, and gas turbines contribute, each one, with $10 \%$ of its generation for reserve power);

- Scenario 7 - Without reserve.

This case considers ten producers, as presented in table 2: 
Table 2 Producers - Case1

\begin{tabular}{|c|c|c|c|}
\hline Producers & Technology & $\mathbf{P}(\mathbf{k W})$ & $\mathbf{P}_{\mathrm{T}}(\mathbf{k W})$ \\
\hline \multirow{3}{*}{1} & Wind farm & 25300 & \multirow{3}{*}{33750} \\
\hline & Wind farm & 7200 & \\
\hline & Wind farm & 1250 & \\
\hline \multirow{3}{*}{2} & Small Hydro & 5500 & \multirow{3}{*}{12500} \\
\hline & Small Hydro & 3500 & \\
\hline & Small Hydro & 4500 & \\
\hline \multirow{4}{*}{3} & Wind farm & 52000 & \multirow{4}{*}{64800} \\
\hline & Fuel Cell & 4000 & \\
\hline & Fuel Cell & 3000 & \\
\hline & Gas Turbine & 5800 & \\
\hline \multirow{2}{*}{4} & Wind farm & 9000 & \multirow{2}{*}{19000} \\
\hline & Small Hydro & 10000 & \\
\hline \multirow{4}{*}{5} & Wind farm & 6500 & \multirow{4}{*}{7200} \\
\hline & Photovoltaic & 250 & \\
\hline & Fuel Cell & 200 & \\
\hline & Gas Turbine & 250 & \\
\hline \multirow[b]{2}{*}{6} & Co-generation & 525 & \multirow{2}{*}{585} \\
\hline & Co-generation & 60 & \\
\hline \multirow{4}{*}{7} & Small Hydro & 8000 & \multirow{4}{*}{10100} \\
\hline & Fuel Cell & 500 & \\
\hline & Fuel Cell & 1000 & \\
\hline & Fuel Cell & 600 & \\
\hline 8 & Co-generation & 3880 & 3880 \\
\hline 9 & Co-generation & 5500 & 5500 \\
\hline 10 & Thermal & $\alpha$ & $\alpha$ \\
\hline
\end{tabular}

Notes: $\mathrm{P}-$ Generation Unit nominal Power; $\mathrm{P}_{\mathrm{T}}-$ Producer nominal Power; 
Having in consideration that this software generates random values, we made ten simulations for each Scenario, with the intention of getting average values.

Producer 10 simulates a thermal plant that it's main function is to assure some level of reserve.

The " $\alpha$ " value chosen for the reserve calculation depends on the used method.

The reserve of each producer is defined by a contract with the VPP.

Table 3 Energy Balancing-Case1

\begin{tabular}{ccccc}
\hline Scenario & $\mathbf{E}_{\mathbf{S}}(\mathbf{M W h})$ & $\mathbf{E}_{\mathbf{D}}(\mathbf{M W h})$ & $\mathbf{E}_{\mathbf{U}}(\mathbf{M W h})$ & $\mathbf{E}_{\mathbf{E}}(\mathbf{M W h})$ \\
\hline 1 & 1823.9 & 1823.9 & 0 & 0 \\
2 & 2545.3 & 2545.3 & 0 & 0 \\
3 & 1823.9 & 1822.1 & 1.8 & 0 \\
4 & 1823.9 & 1801.6 & 22.3 & 0 \\
5 & 1702.4 & 1696.6 & 5.8 & 0 \\
6 & 1702.4 & 1662.5 & 39.9 & 0 \\
7 & 1823.9 & 1729.0 & 94.9 & 0 \\
\hline
\end{tabular}

Notes: $\quad \mathrm{E}_{\mathrm{S}}$ - Sold Energy; $\quad \mathrm{E}_{\mathrm{D}}$ - Delivered Energy;

$\mathrm{E}_{\mathrm{U}}$ - Undelivered Energy; $\mathrm{E}_{\mathrm{E}}$ - Exciding Energy;

Table 4 Market Results - UK 28/09/2005 - Case 1

\begin{tabular}{ccccc}
\hline Scenario & Sells $(\boldsymbol{\epsilon})$ & Costs $(\boldsymbol{\epsilon})$ & Penalty $(\boldsymbol{\epsilon})$ & Profit $(\boldsymbol{\epsilon})$ \\
\hline 1 & 77893.44 & 143943.13 & 0 & -66049.70 \\
2 & 108399.02 & 158501.82 & 0 & -50102.80 \\
3 & 77803.83 & 113104.57 & 92.85 & -35393.60 \\
4 & 76816.07 & 102353.51 & 1177.73 & -26715.17 \\
5 & 72430.21 & 100916.77 & 317.94 & -28804.51 \\
6 & 70867.00 & 89505.85 & 2010.97 & -20649.82 \\
7 & 73668.65 & 89112.13 & 4460.64 & -19904.12 \\
\hline
\end{tabular}


Table 5 Market Results - UK 28/11/2005 - Case 1

\begin{tabular}{ccccc}
\hline Scenario & Sells $(\boldsymbol{\epsilon})$ & Costs $(\boldsymbol{\epsilon})$ & Penalty $(\boldsymbol{\epsilon})$ & Profit $(\boldsymbol{\epsilon})$ \\
\hline 1 & 203619.21 & 143943.13 & 0 & 59676.07 \\
2 & 285249.14 & 158501.82 & 0 & 126747.32 \\
3 & 203437.77 & 113104.57 & 293.23 & 90039.98 \\
4 & 200944.61 & 102353.51 & 3445.10 & 95146.00 \\
5 & 189248.49 & 100916.77 & 1000.26 & 87331.46 \\
6 & 185185.20 & 89505.85 & 5951.58 & 89727.78 \\
7 & 192982.50 & 89112.13 & 13837.17 & 90033.20 \\
& & & & \\
\hline
\end{tabular}

Table 6 Market Results - France 28/09/2005 - Case 1

\begin{tabular}{ccccc}
\hline Scenario & Sells $(\boldsymbol{\epsilon})$ & Costs $(\boldsymbol{\epsilon})$ & Penalty $(\boldsymbol{\epsilon})$ & Profit $(\boldsymbol{\epsilon})$ \\
\hline 1 & 88340.50 & 143943.13 & 0 & -55602.63 \\
2 & 123959.95 & 158501.82 & 0 & -34541.87 \\
3 & 88232.07 & 113104.57 & 147.52 & -25020.02 \\
4 & 87117.69 & 102353.51 & 1568.75 & -16804.58 \\
5 & 82072.59 & 100916.77 & 437.08 & -19281.26 \\
6 & 80321.94 & 89505.85 & 2675.85 & -11859.76 \\
7 & 83534.20 & 89112.13 & 6269.24 & -11847.17 \\
\hline
\end{tabular}

Table 7 Market Results - France 28/11/2005 - Case 1

\begin{tabular}{ccccc}
\hline Scenario & Sells $(\boldsymbol{\epsilon})$ & Costs $(\boldsymbol{\epsilon})$ & Penalty $(\boldsymbol{\epsilon})$ & Profit $(\boldsymbol{\epsilon})$ \\
\hline 1 & 277819.86 & 143943.13 & 0 & 133876.72 \\
2 & 391749.85 & 158501.82 & 0 & 233248.03 \\
3 & 277607.98 & 113104.57 & 220.50 & 164282.92 \\
4 & 273829.62 & 102353.51 & 4252.67 & 167223.44 \\
5 & 257895.20 & 100916.77 & 1202.09 & 155776.25 \\
6 & 252193.55 & 89505.85 & 7207.17 & 155480.52 \\
7 & 262820.13 & 89112.13 & 15746.93 & 157961.07 \\
& & & & \\
\hline
\end{tabular}

The values in tables 4 to 7 are based on the values presented by the entities responsible for the market management and/or for the balancing mechanisms that, in the case of UK and France, are, respectively, UKPX/Elexon and PowerNext/RTE (Ukt, Elx, Pnt, Rte, 2006). 
The cost evaluation associated with the operation of the producers has been done with software available in the Retscreen web site (Retscreen, 2006), where, in accordance with specifications previously defined, it is possible to determine the costs of generation for the different technologies.

The VPP costs are calculated using the values proposed by the producers, the cost of the reserve, and costs associated with VPP management and operation services.

Analyzing the values presented in Tables 4 to 7, it can be concluded that in the space of two months, between September and November of 2005, the expectations of the VPP are totally different.

In both markets, we got results from about ten thousands Euros of losses in September to hundreds thousands Euros of profits in November. These variations reflect the instability of the oil markets, on this period of time.

It is important to point out that the undertaken calculations did not take into account any type of subsides or benefits, that usually are attributed to DG.

It is interesting to verify that, although both markets present similar behaviours, the French market has considerably higher profits for all the scenarios than the English market, relative to November.

Considering the month of September and comparing the several scenarios we can verify that lesser the reserve, lesser the financial losses.

In November the situation is totally different. The scenario that presents greater profit is Scenario 2, with higher sold energy and no penalties.

In this example, a contract for 6 months with a thermal plant was simulated with a price of $52 € / \mathrm{MWh}$.

As prices increased significantly, if all the contracted energy to the thermal plant was sold by the VPP probably there would be even better results.

Analyzing Scenarios 5, 6 and 7, it can be verified that the differences between the values of the profits are relatively small $( \pm 3 \%)$. However, the penalties values are substantially different, what means that using the strategies considered in Scenario 5 the VPP will be able to reduce significantly the penalties and improve its credibility without affecting substantially the profits.

Even in Scenario 6, using only reserve power from its associates, the VPP reduces significantly it's penalties.

In the second case study, the simulation considers a three wind power producers association. Each one of these producers has a co-generation unit with a nominal power of about $10 \%$ of the wind farm capacity.

Table 8 Producers - Case1

\begin{tabular}{cccc}
\hline Producers & Technology & $\mathbf{P}(\mathbf{k W})$ & $\mathbf{P}_{\mathbf{T}}(\mathbf{k W})$ \\
\hline 1 & Wind farm & 30000 & 33030 \\
\hline 2 & Co-generation & 3030 & 21000 \\
\hline 3 & Wind farm & 20000 & 14250 \\
\hline & Co-generation & 2100 & \\
\hline
\end{tabular}

Notes: $\mathrm{P}$ - Generation Unit nominal Power; $\mathrm{P}_{\mathrm{T}}-$ Producer nominal Power; 
The co-generation will serve as support of the wind farms, to compensate the generation variations of this type of producing units.

In this case study, hall the required reserve is assured by VPP own means.

In this case the simulated scenarios are the following:

- Scenario 1 - Reserve assured by the producers, with all the co-generation production as reserve;

- Scenario 2 - Reserve assured by the producers, with $75 \%$ of the cogeneration production as reserve;

- Scenario 3 - Reserve assured by the producers, with $50 \%$ of the cogeneration production as reserve;

- Scenario 4 - Reserve assured by the producers, with $25 \%$ of the cogeneration production as reserve;

- $\quad$ Scenario 5 - Without reserve.

Table 9 Energy Balancing - Case2

\begin{tabular}{ccccc}
\hline Scenario & $\mathbf{E}_{\mathbf{S}}(\mathbf{M W h})$ & $\mathbf{E}_{\mathbf{D}}(\mathbf{M W h})$ & $\mathbf{E}_{\mathbf{U}}(\mathbf{M W h})$ & $\mathbf{E}_{\mathbf{E}}(\mathbf{M W h})$ \\
\hline 1 & 529.41 & 570.29 & 3.17 & 44.06 \\
2 & 567.69 & 574.47 & 0.92 & 7.70 \\
3 & 605.97 & 614.64 & 14.05 & 22.72 \\
4 & 644.25 & 633.77 & 11.85 & 1.38 \\
5 & 682.53 & 659.80 & 32.00 & 9.27
\end{tabular}

Notes: $\quad \mathrm{E}_{\mathrm{S}}$ - Sold Energy; $\quad \mathrm{E}_{\mathrm{D}}$ - Delivered Energy;

$\mathrm{E}_{\mathrm{U}}-$ Undelivered Energy; $\mathrm{E}_{\mathrm{E}}-$ Exciding Energy;

Table 10 Market Results - UK 28/09/2005 - Case 2

\begin{tabular}{ccccc}
\hline Scenario & Sells $(\boldsymbol{\epsilon})$ & Costs $(\boldsymbol{\epsilon})$ & Penalty $(\boldsymbol{\epsilon})$ & Profit $(\boldsymbol{\epsilon})$ \\
\hline 1 & 22779.48 & 29940.42 & -1540.54 & -5620.40 \\
2 & 24408.45 & 30159.54 & -257.59 & -5493.50 \\
3 & 25915.56 & 32268.65 & -210.94 & -6142.14 \\
4 & 27163.82 & 33273.09 & 533.57 & -6642.84 \\
5 & 28287.05 & 34639.25 & 1143.66 & -7495.86 \\
\hline
\end{tabular}


Table 11 Market Results - UK 28/11/2005 - Case2

\begin{tabular}{ccccc}
\hline Scenario & Sells $(\boldsymbol{\epsilon})$ & Costs $(\boldsymbol{\epsilon})$ & Penalty $(\boldsymbol{\epsilon})$ & Profit $(\boldsymbol{\epsilon})$ \\
\hline 1 & 59484.73 & 29940.42 & -4282.01 & 33826.32 \\
2 & 63786.14 & 30159.54 & -685.81 & 34312.41 \\
3 & 67806.14 & 32268.65 & -434.36 & 35971.86 \\
4 & 71190.49 & 33273.09 & 1574.26 & 36343.15 \\
5 & 74244.19 & 34639.25 & 3840.40 & 35764.54 \\
\hline
\end{tabular}

Table 12 Market Results - France 28/09/2005 - Case 2

\begin{tabular}{ccccc}
\hline Scenario & Sells $(\boldsymbol{\epsilon})$ & Costs $(\boldsymbol{\epsilon})$ & Penalty $(\boldsymbol{\epsilon})$ & Profit $(\boldsymbol{\epsilon})$ \\
\hline 1 & 25704.33 & 29940.42 & -1953.05 & -2283.04 \\
2 & 27572.31 & 30159.54 & -306.98 & -2280.25 \\
3 & 29312.92 & 32268.65 & -225.05 & -2730.68 \\
4 & 30743.58 & 33273.09 & 712.38 & -3241.88 \\
5 & 32041.51 & 34639.25 & 1625.54 & -4223.28 \\
\hline
\end{tabular}

Table 13 Market Results - France 28/11/2005 - Case 2

\begin{tabular}{ccccc}
\hline Scenario & Sells $(\boldsymbol{\epsilon})$ & Costs $(\boldsymbol{\epsilon})$ & Penalty $(\boldsymbol{\epsilon})$ & Profit $(\boldsymbol{\epsilon})$ \\
\hline 1 & 81360.90 & 29940.42 & -2549.36 & 53969.84 \\
2 & 87283.41 & 30159.54 & -409.29 & 57533.15 \\
3 & 92810.66 & 32268.65 & 905.60 & 59636.41 \\
4 & 97357.83 & 33273.09 & 2006.83 & 62077.91 \\
5 & 101522.60 & 34639.25 & 5084.86 & 61798.49 \\
\hline
\end{tabular}

Such as in the previous case, the results of the considered September day have been negative.

For the considered November day, the results have been positive, and the scenario that presents greater profit is scenario 4 . In this scenario the reserve is only $2.5 \%$ of the wind generation, however it is enough to reduce the penalties by half and to develop some profits.

Comparing scenarios 3 and 5, we can see that, in France, scenario 5 is more advantageous; however, in UK, it is the inverse. On the other hand, in scenario 3, in France, the penalties are positive and in England the penalties are negative. While in the first one we have energy surplus, in the second we have energy shortage, modifying the penalty regime. 


\section{Conclusions and Future Work}

In this paper we presented some VPP reserve management strategies. The main goal is to decide the best VPP management strategy for generation and reserve. The VPP must know all the market rules and the balancing mechanisms, in order to adjust its own strategy to improve its performance in the electricity market.

With a correct reserve management, according to the used technologies, the VPP has higher probability to deliver all the energy that it already sold, minimizing the penalties.

There are markets where the incomplete fulfilment of all rules established in the contracts, do not impose any type of penalties. However, the VPP, such as the others agents in the market, will have to fulfil all the agreements, to guarantee a good functioning.

The paper uses a simulation tool (ViProd), developed, by the authors, in Maltab/Simulink, to simulate the operation of a Virtual Power Producer (VPP). This tool allows creating several producers using several generation technologies and simulates the internal generation scheduling as well the interaction between the VPP and the electricity market.

This paper includes two case studies to demonstrate the results of all considered reserve management strategies in two different electricity markets, France and UK, in two days of different months, September and November. The results have been obtained by Viprod, considering each market characteristics and real prices. With Viprod a VPP can analyse is own data and decide the most adjusted reserve management strategy to each situation.

Presently, we are working on the integration of ViProd with an electricity market simulator - MASCEM (Praça, 2003) that has been developed in GECAD as a multi-agent system. This integration will allow analyzing the results of several VPP strategies when acting in the market.

As future work we will model our simulation tools beyond the simple concept of a seller-buyer model, introducing the VPP, bringing new features, like the representation of the intermediate energy trades.

The new developed tools, allow a more complete understanding of the market, showing the efficiency of a VPP operating in a competitive market, versus a single isolated producer market.

Redesigning the system to archive a new set of features embedded on the intelligent agents interaction, built upon a redesigned environment will introduce those new possibilities in the system.

\section{Acknowledgements}

The authors would like to acknowledge FCT, FEDER, POCTI, POSI, POCI and POSC for their support to R\&D Projects and the GECAD Unit. 


\section{References}

Bertani, Bertani, A.; Bossi, C.; Fornari, F.; Massucco, S.; Spelta, S.; Tivegna, F, "A microturbine generation system for grid connected and islanding operation", Power Systems Conference and Exposition, 2004. IEEE PES 10-13 Oct. 2004 Page(s):360 365 vol.1.

Consentec, Consentec, Frontier Economics, "Benefits and practical steps towards the integration of intraday electricity markets and balancing mechanisms”, 2005

Hatziargyriou, Nikos Hatziargyriou; Sakis Meliopoulos, "Distributed energy sources: technical challenges", Power Engineering Society Winter Meeting, 2002. IEEE Vol. 2, 27-31 Jan. 2002 Page(s):1017-1022

IEA, International Energy Agency, "Distributed Generation in Liberalised Electricity Markets", 2002

Katti, K. Katti, Mohan K. Khedkar , "Alternative energy facilities based on site matching and generation unit sizing for remote area power supply ", Renewable Energy, Vol. 32, Issue 8, Pages 1346-1362, 2007

Kehler, J. Kehler, M. Hu, D. McCrank, "Market Evolution to Accommodate High Wind Power Penetration” IEEE PES - Power Systems Conference \& Exposition, 2006

Khattam, Walid El-Khattam, Student Member, IEEE, Kankar Bhattacharya, Senior Member, IEEE, Yasser Hegazy, Member, IEEE, and M. M. A. Salama, Fellow, IEEE, "Optimal Investment Planning for Distributed Generation in a Competitive Electricity Market”, IEEE Transactions on Power Systems, vol. 19, No.3, August 2004

Morais, Hugo Morais, Marílio Cardoso, Luís Castanheira, Zita Vale, Member, IEEE, Isabel Praça, "Producers Remuneration by Virtual Power Producers", WSEAS Transactions on Power Systems, Volume 1, nº 7, pág. 1358-1365, July, 2006

Morais, Hugo Morais, Marílio Cardoso, Luís Castanheira, Zita Vale, Member, IEEE, Isabel Praça, "A Decision-Support Simulation Tool for Virtual Power Producers", International Conference on Future Power Systems, 2005

Oxera, OXERA Consulting Ltd, "Electricity Liberalisation - Indicators in Europe”, 2001 